\title{
On the early development of human dental lamina
}

By

\section{Tadahiro Ooé}

(Department of Anatomy, Tokyo Medical and Dental University)

The development of the teeth and their anlage have been studied by a large number of anatomists and odontologists. Nevertheless there still remain problems untouched by previous authors in the dental embryology. Careful reviews of previous papers reveal that little is known about very early development of human dental lamina. This is why most of the previous text-books carry only schematic figures as illustrations of the dental lamina (Fig. 29 in E i d m a n n, 1923; Fig. 166 in M e y e r, 1951 ; Fig. 146 in S i c h e r und Tand le r, 1928 etc.).

In such circumstances special attention should be paid to the description of Rös e (1893) about a specimen in which the dental lamina was interrupted in its extension and to the statement of $\mathrm{Me} \mathrm{ye} \mathrm{r}$ that the first anlage of the dental lamina comes to development in an insular pattern. Recently E n oki (1944) found that the dental lamina of the guinea-pig is formed separately in the front teeth and molar regions, which are in a later period united to one continuous strand.

In the present work, which is partly the continuation of my previous paper, I studied the human dental lamina in its earlier stages of development and made careful, stereoscopical observations, paying special attentions to the plastic formation of the oral cavity.

Materials used are presented in the following list.

Method employed is the same as in my previous paper (1956). Many reconstruction models of the ectoderm parts were made, the mesoderm being taken off. All figures presented were drawn free hand. Since they illustrate the views from the mesodermal side, structures such as facial processes and tongue are seen in figures as hollowed and the epithelial ingrowth into the mesoderm and the depression of oral cavity appear elevated in figures. 


\begin{tabular}{|c|c|c|c|c|c|}
\hline & & List of mate & & & \\
\hline $\begin{array}{c}\text { Number of } \\
\text { embryos }\end{array}$ & $\begin{array}{l}\text { Crown-rump } \\
\text { length (mm) }\end{array}$ & $\begin{array}{l}\text { Thickness of } \\
\text { section }(\mu .)\end{array}$ & $\begin{array}{l}\text { Direction of } \\
\text { sections }\end{array}$ & & Remarks \\
\hline 111 & 4 & 10 & $\mathbf{S}$ & & \\
\hline 122 & 6 & 20 & $\mathrm{~S}$ & & reconstructed \\
\hline 126 & 8 & $" \prime$ & $\mathbf{S}$ & & \\
\hline$*$ & $" \prime$ & 6 & $\mathbf{S}$ & & \\
\hline 123 & 9 & 20 & $\mathbf{S}$ & & \\
\hline 124 & $\prime \prime$ & $" 1$ & $\mathrm{~F}$ & & \\
\hline 98 & " & "l & $\mathbf{S}$ & & reconstructed \\
\hline 19 & 10 & 12 & $\mathbf{S}$ & & \\
\hline 90 & 11 & 15 & $\mathbf{S}$ & & \\
\hline 112 & $"$ & 20 & $\mathbf{S}$ & 、 & reconstructed \\
\hline 99 & 13 & $"$ & $\mathbf{S}$ & & \\
\hline 91 & $" \prime$ & 15 & $\mathbf{S}$ & & \\
\hline 113 & $" \prime$ & 20 & F & & \\
\hline 109 & 14 & $" \prime$ & $\mathbf{S}$ & & reconstructed \\
\hline 110 & $" \prime$ & " & $\mathbf{S}$ & & \\
\hline 101 & 15 & $" \prime$ & $\mathrm{S}$ & & reconstructed \\
\hline 127 & " & " & $\mathbf{S}$ & & \\
\hline 128 & $" 1$ & $" \prime$ & $\mathbf{S}$ & & reconstructed \\
\hline 114 & " & $" \prime$ & $\mathbf{S}$ & & \\
\hline 100 & 16 & $\prime \prime$ & $\mathbf{S}$ & & reconstructed \\
\hline 92 & $" \prime$ & 15 & $\mathbf{H}$ & & \\
\hline 1 & 17 & " & $\mathbf{S}$ & & \\
\hline 79 & " & 10 & $\mathbf{F}$ & & \\
\hline 93 & $\prime \prime$ & $" \prime$ & $\mathbf{F}$ & & \\
\hline
\end{tabular}

Note: $\mathrm{S}$ : sagittal, $\mathrm{F}$ : frontal, $\mathrm{H}$ : horizontal section. * This embryo is borrowed and the serial number is missing.

In the following description I divide the developmental process of the dental anlage in several stages and to each stage the corresponding specimen numbers are added. The most characteristic features of the stage are given in italic. Explanations of the figures follow and finally, in case of the presence, remarks on variations are made.

\section{Observations in the lower jaw}

Stage I (No. 123, No. 90, No. 126 and No. 98)

In the first stage of development the dental lamina only appears as a thickening of the oral epithelium.

Fig. 1 shows the reconstruction model of No. $98(9 \mathrm{~mm})$. The oral cavity, which is narrow antero-posteriorly, bends and continues into the branchial gut. The median portion of the mandibular process is depressed. Thickening of the oral epithelium spreads from the 


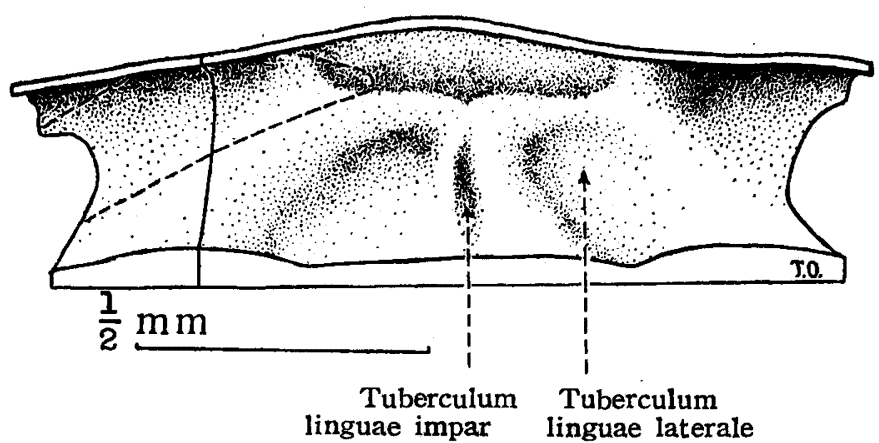

Fig. 1. No. $98(9 \mathrm{~mm})$.

margin of the digestive tube to the vicinity of the median line. This area is surrounded by a dotted line in the figure. The portion where tongue, mandibular process and medial portion of the latter meet with each other is elevated, that is, depressed in nature. This region seems to correspond to the site of the future molar.

Fig. 11 (plate) shows the epithelial thickening in this specimen. The line in Fig. 1 indicates the section from which the photograph, Fig. 11, was taken.

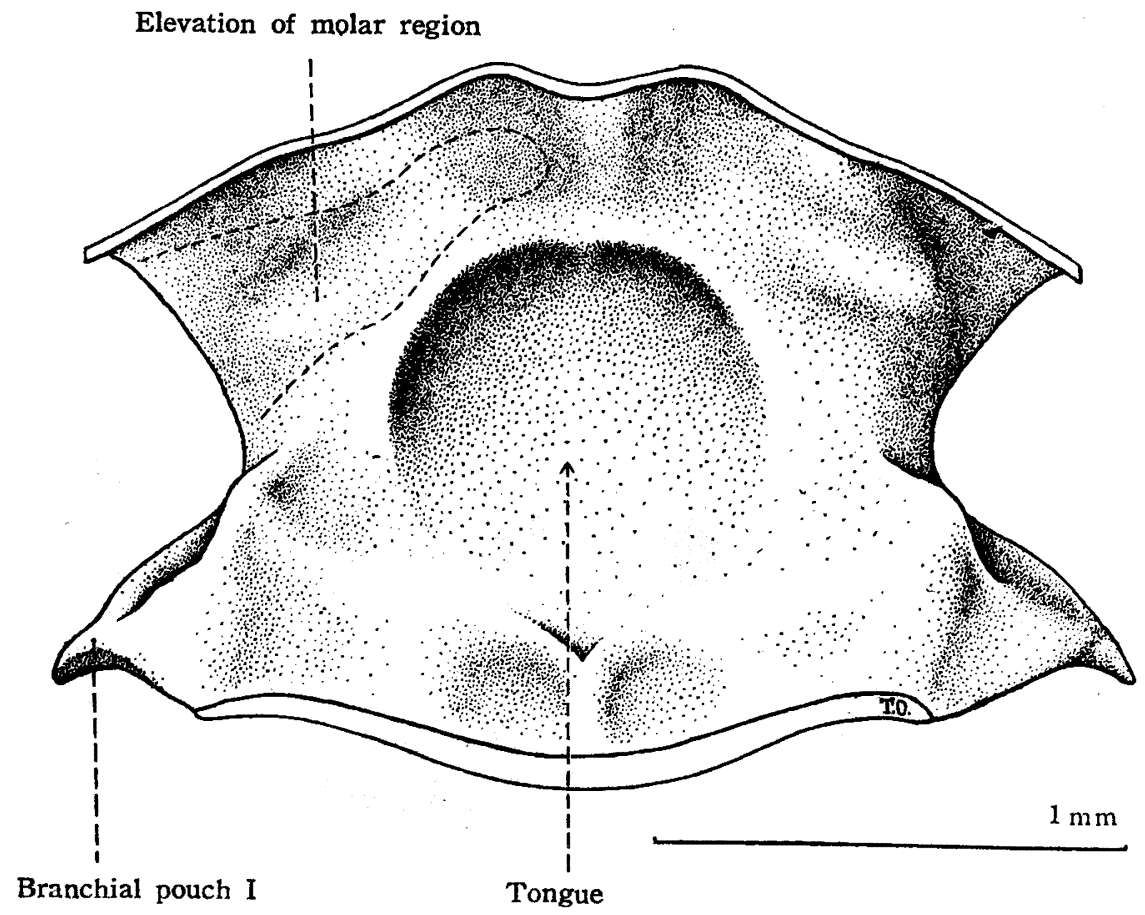

Fig. 2. No. $112(11 \mathrm{~mm})$. 
Stage II (No. 19, No. 99 and No. 112)

The elevation of molar region mentioned above is now separated from the tongue.

Fig. 2 shows the model of No. $112(11 \mathrm{~mm})$. The area of the epithelial thickening is indicated by a dotted line. The prospective molar region is elevated but the elevation is partly accentuated by the depression of the oral cavity.

Stage III (No. 91, No. 109 and No. 110)

The epithelial ingrowth begins also in the anterior part of the prospective dental arch while it is still scarcely recognizable in the space between this part and the molar region.

Anterior ingrowth

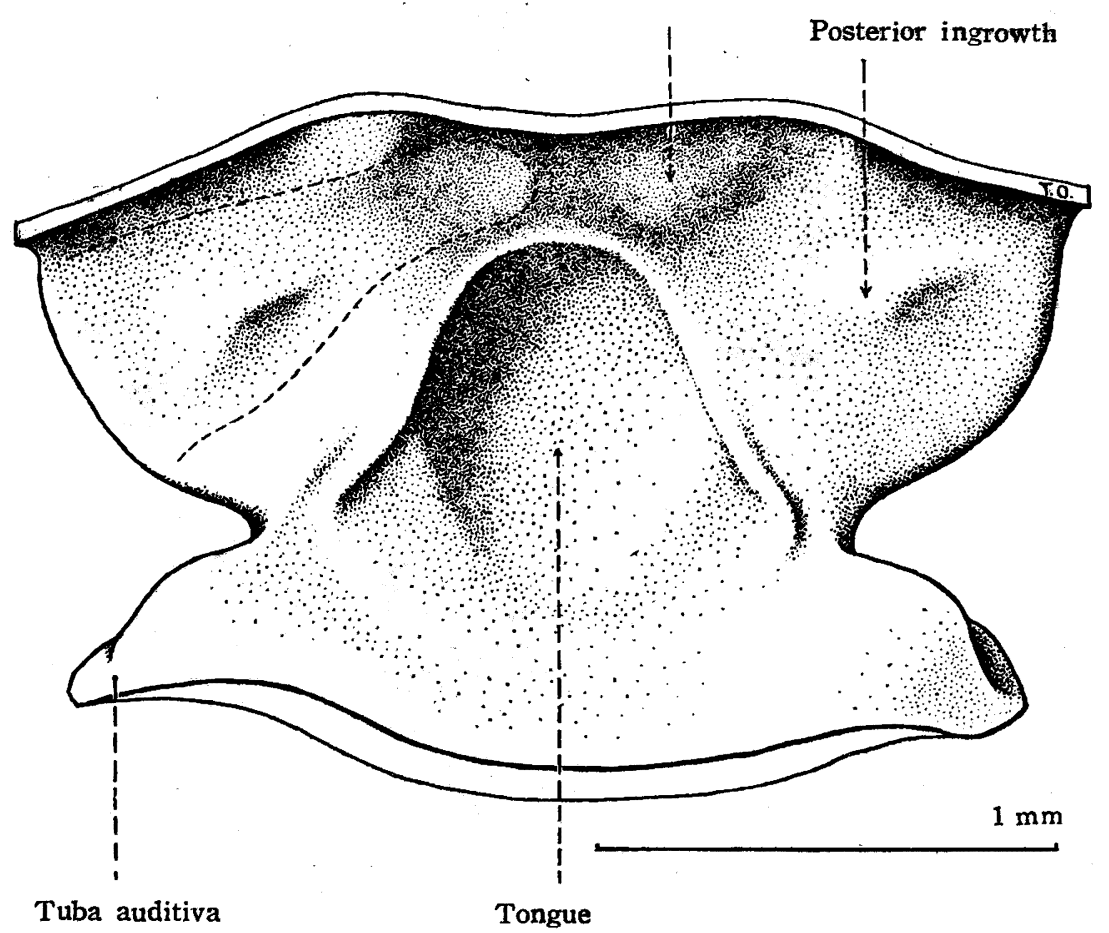

Fig. 3. No. $109(14, \mathrm{~mm})$.

Fig. 3 demonstrates the model of No. $109(14 \mathrm{~mm})$. The oral cavity has remarkably grown in antero-posterior diameter. In the hollowed medial portion of the lower jaw a flat ingrowth has appeared and in the molar region the big ingrowth slightly directed to the lingual side is seen as in the former stages. In No. 91 the anterior ingrowth is not so advanced as in other specimens. 
Fig. 12 (Plate) shows the three sections of the embryo, No. 109. $A$ represents the anterior ingrowth, $C$ the posterior ingrowth and $B$ the space between $\mathrm{A}$ and $\mathrm{C}$, where the ingrowth is scarcely seen.

Stage IV (No. 101, No. 127, No. 100, No. 128 and No. 1)

The ingrowth of the oral epithelium comes to spread on the entire length of the future dental arch but the so-called dental lamina is inconspicuous in the space between the future germs of $i_{2}$ and $c$. At this stage the right and left dental lamina becomes at last continuous with each other on the median line.

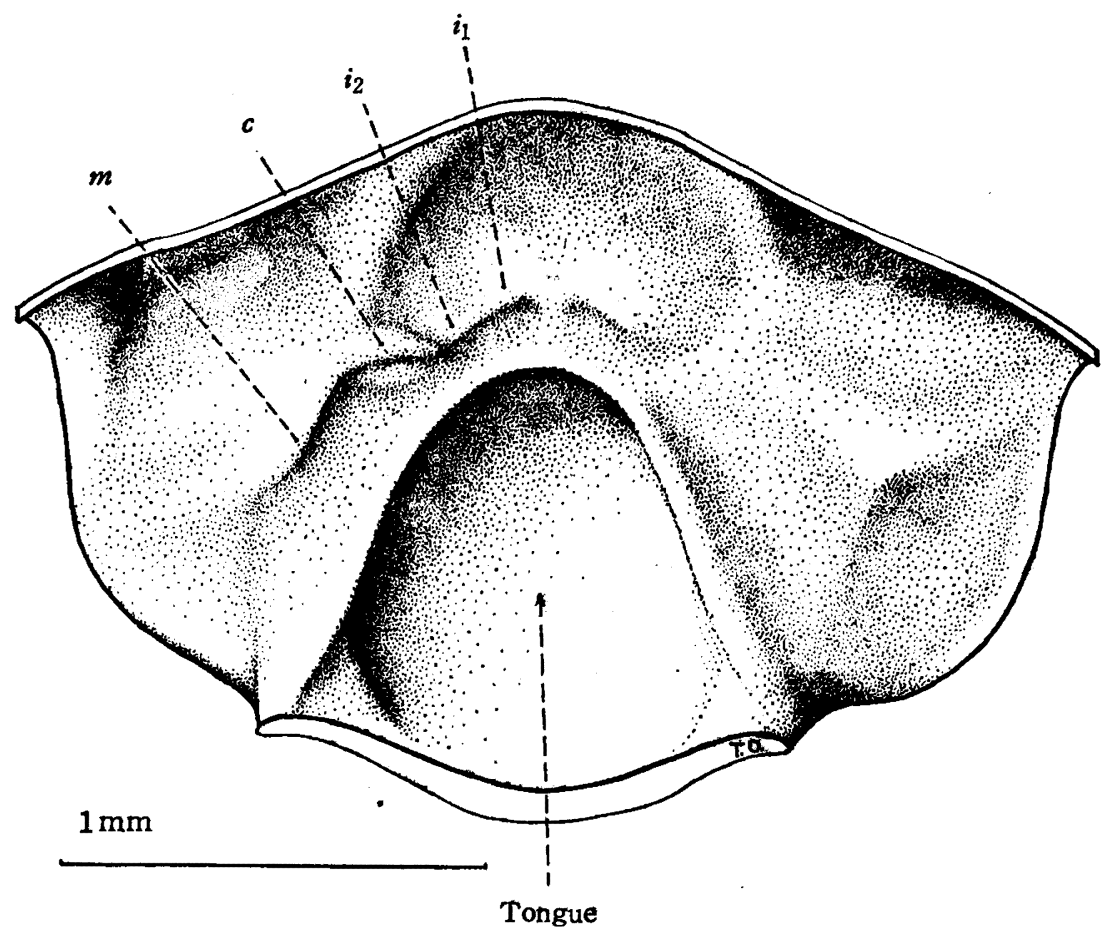

Fig. 4. No. $101(15 \mathrm{~mm})$.

Fig. 4 represents the model of No. $101(15 \mathrm{~mm})$. The anterior ingrowth extends in distal direction and gives rise to the germ of $i_{2}$, while the distal molar ingrowth terminates mesially with a small ridge which may be considered as the area of germ $c$. Fig. 13 (Plate) shows several sections of this specimen. Note the different aspects of the epithelial ingrowth among each dental anlage.

In Fig. 5 the model of No. $100(16 \mathrm{~mm})$ is illustrated. The dental lamina describes a wavy contour. Note above all the deep notch in the dental lamina between the germs of $i_{2}$ and $c$. As a variation, the 


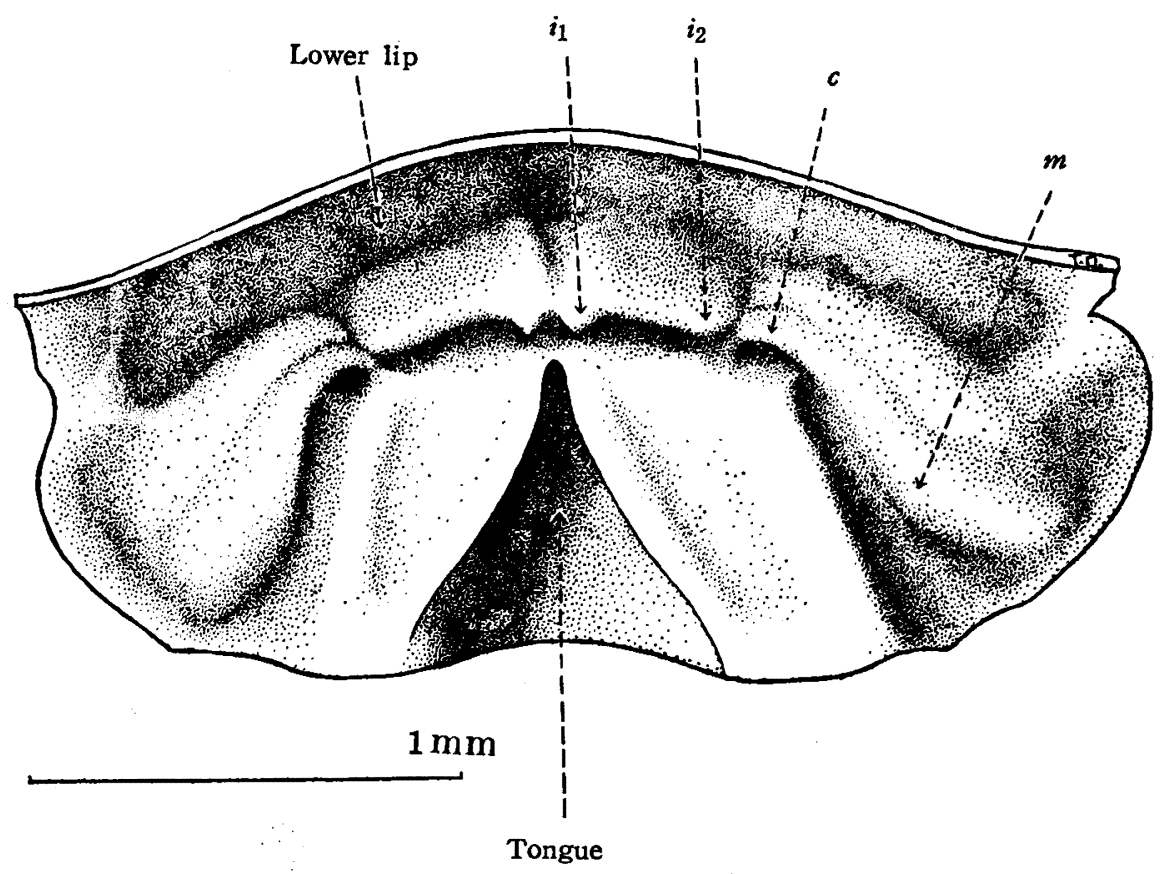

Fig. 5. No. 100 (16 mm).

notch was especially deep on the left side of No. $1(17 \mathrm{~mm})$. In No. $114(15 \mathrm{~mm})$ the free margin of the dental lamina is cut in between the germs of $c$ and $m$.

From this stage on the difference of ingrowth direction among the germs becomes more and more apparent. Descriptions of the later stages might be omitted as they were treated in my previous paper.

\section{Observations in the upper jaw}

Stage I (No. 123, No. 90, No. 126 and No. 98)

Before the maxillary processes fuse with the medial nasal processes, the thickening of the oral epithelium appears on each of the processes.

Fig. 6 is an upper-posterior view of the model No. $98(9 \mathrm{~mm})$. The nasal pits are separated widely from each other. On the medial nasal process an ingrowth is seen and its distal end is continued into the nasal pit. Through observation of other specimens it was ascertained that the epithelial thickening takes place prior to the ingrowth. On the maxillary process on the other hand the area of the epithelial 


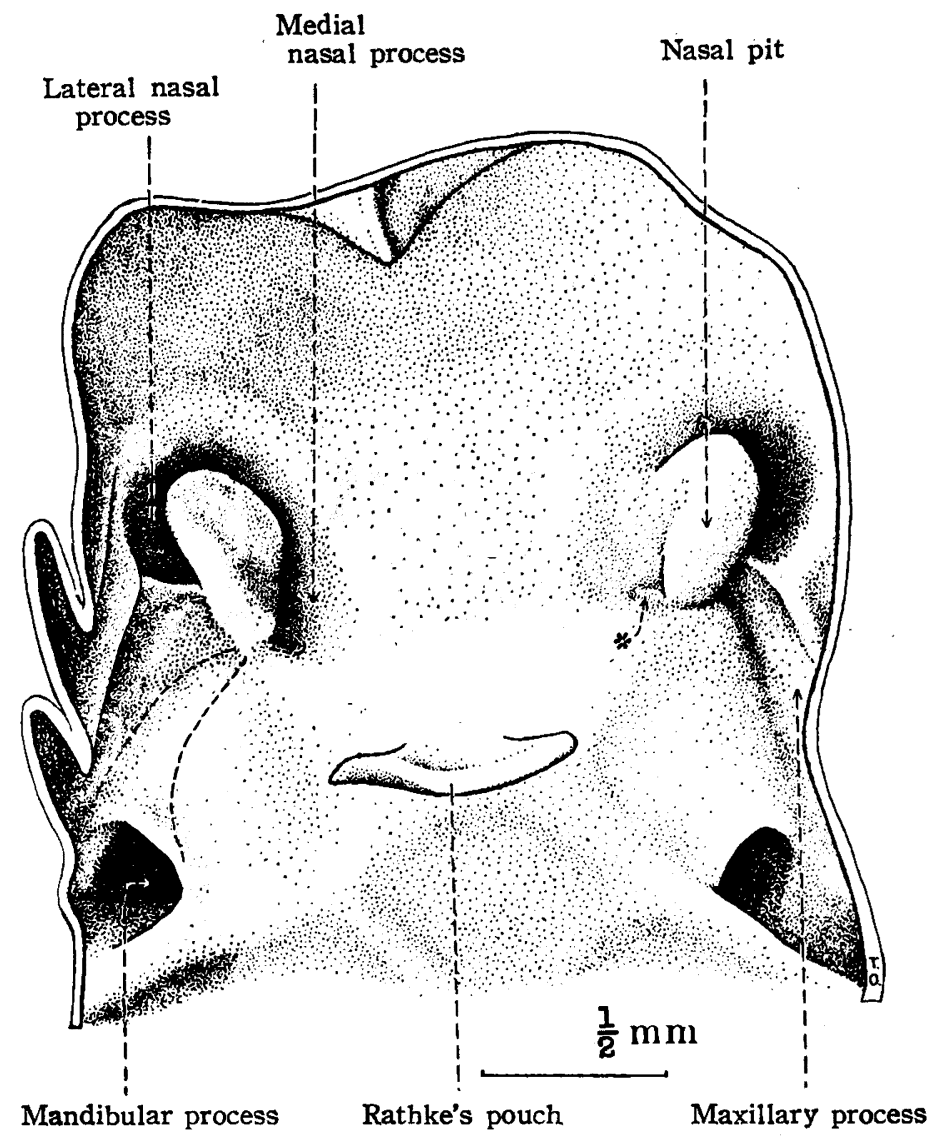

Fig. 6. No. $98(9 \mathrm{~mm})$. * anterior ingrowth

thickening is extending from the nasal pit to the margin of the oral cavity, as indicated by a dotted line in the figure.

Stage II (No. 112 and No. 99)

The medial nasal process bulges then into the globular process of His. The epithelial thickening in this process is flattened at the distal end and on the maxillary process there appears an elevation.

In Fig. 7 a model of No. $112(11 \mathrm{~mm})$ is represented. In the globular process the epithelial ridge present in the former stage is now flattened in the distal end so that it appears as cut off from the nasal pit. In the maxillary process there is an elevation, accentuated partly by the depression of the oral cavity and partly by the epithelial thickening which covers the area enclosed by a dotted line. The portion anterior to this elevation is pars facialis and posterior to it pars oralis of the maxillary process. 


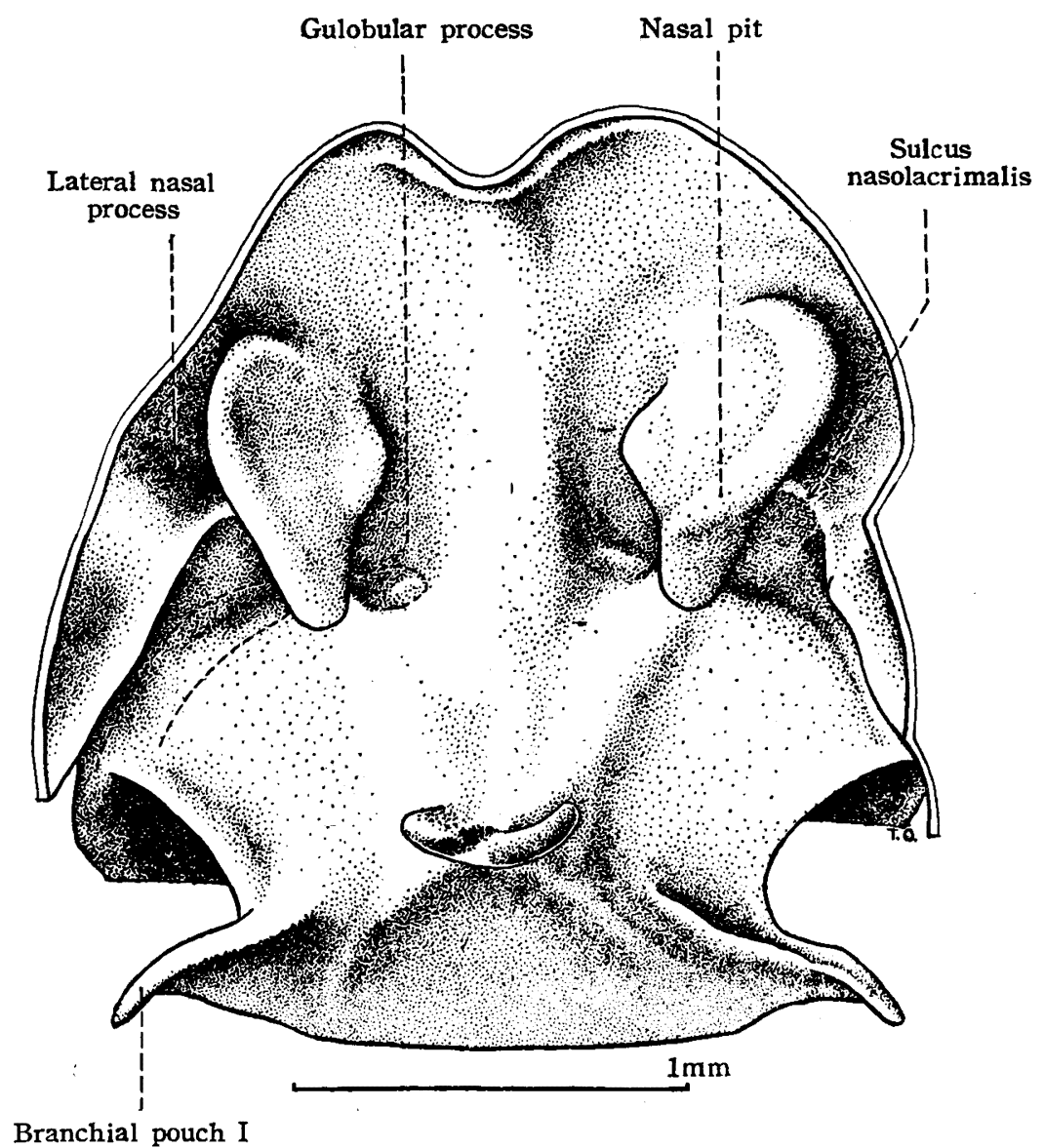

Fig. 7. No. $112(11 \mathrm{~mm})$.

In the embryo No. 99, the same stage, the medial ridge of the globular process was still continuous to the nasal pit on one side, while on the opposite side these parts were already separated from each other.

Stage III (No. 19, No. 109, No. 110, No. 128, No. 101, No. 127 and No, 100)

The facial processes are fused with each other on the ventral side of the nasal pit so that the latter now forms the nasal tube. From this period on the thickening and ingrowth of the oral epithelium are noticeable along the entire length of the future dental arch. Along the seam of the medial nasal and maxillary processes the oral epithelium is slightly elevated against the mesoderm and the dental lamina bends palatinalwards at this point. 
The epithelial ridge on the globular process which was flattened at its distal extremity in the foregoing stage may be regarded as the germ of $i_{1}$, but in some specimens (No. 91 and right side of No. 19) it still continues to the nasal tube. The distal region of the dental lamina is more elevated but as in the lower jaw this elevation is partly caused by a depression of the oral cavity. This area corresponds to the future molar region. The epithelial elevation in former stages is located anterior to this area. Between these two ingrowthes $-i_{1}$ and $m-I$ could not distinguish any dental germ in some specimens (No. 91 and 101). In other, however, the area in front of the primitive choana was elevated to the presumable germ of $i_{2}$. In such cases the

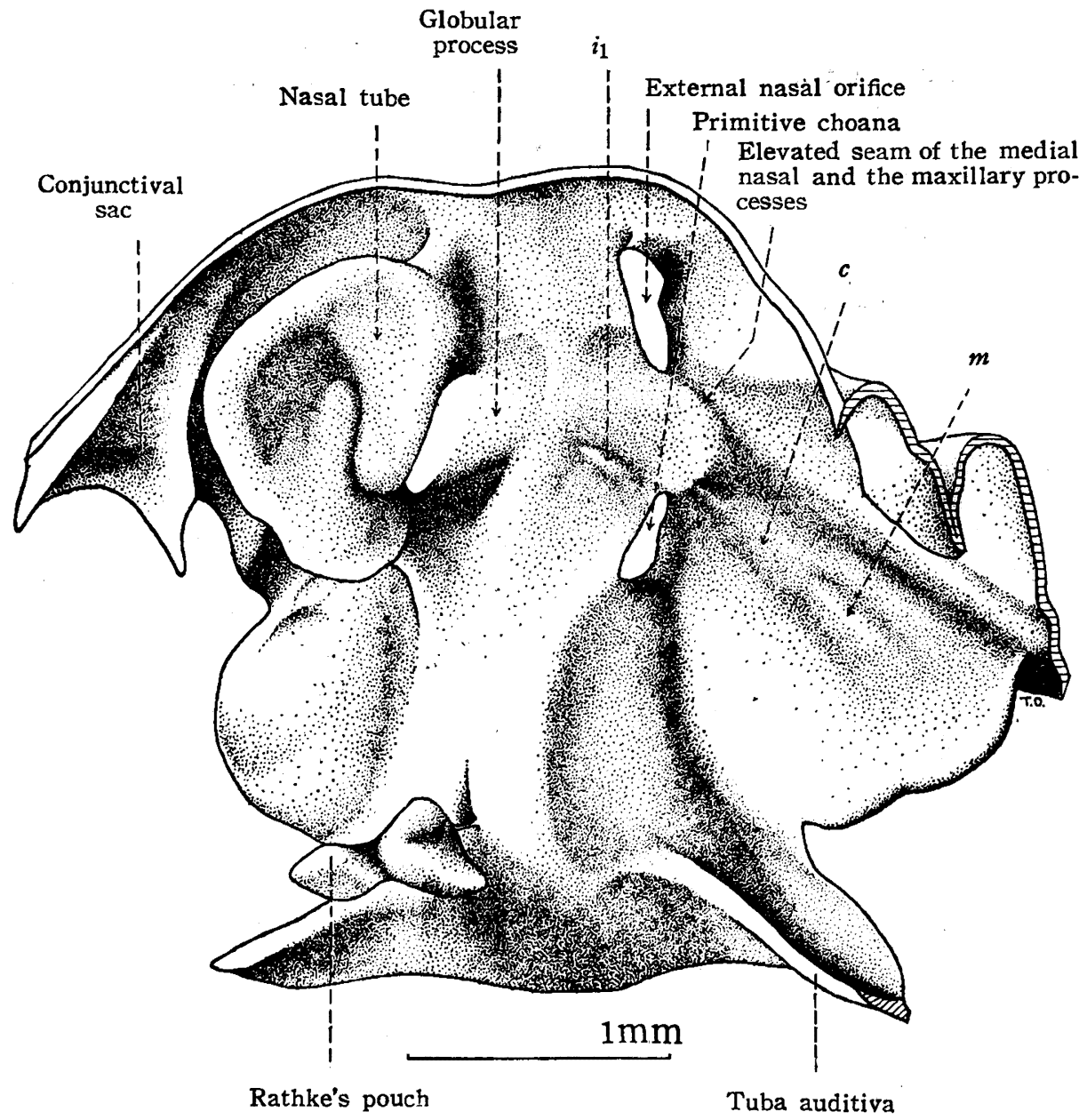

Fig. 8. No. $128(15 \mathrm{~mm})$. 
area of the germ $c$ was a very flattened ingrowth.

On the median line a wide space still separates the germs $i_{1}$ of both sides as in forner stages.

Fig. 8 is a dextro-posterior view of the model No. $128(15 \mathrm{~mm})$. On the right side the nasal cavity is taken off, being cut at the external nasal orifice and at the primitive choana so that the dental arch is well exposed. The most mesial part of the epithelial thickening on the maxillary process seems to be the germ $i_{2}$, it is flattened at its distal end to continue to the germ $c$ and is again elevated in the molar region.

Fig. 13 (Plate) illustrates the serial section of the specimen, No. $101(15 \mathrm{~mm})$. Note the different aspects of the epithelial ingrowth.

Fig. 9 represents the model of No. $100(16 \mathrm{~mm})$; the nasal cavities are taken off on both sides, being cut at the primitive choana. The

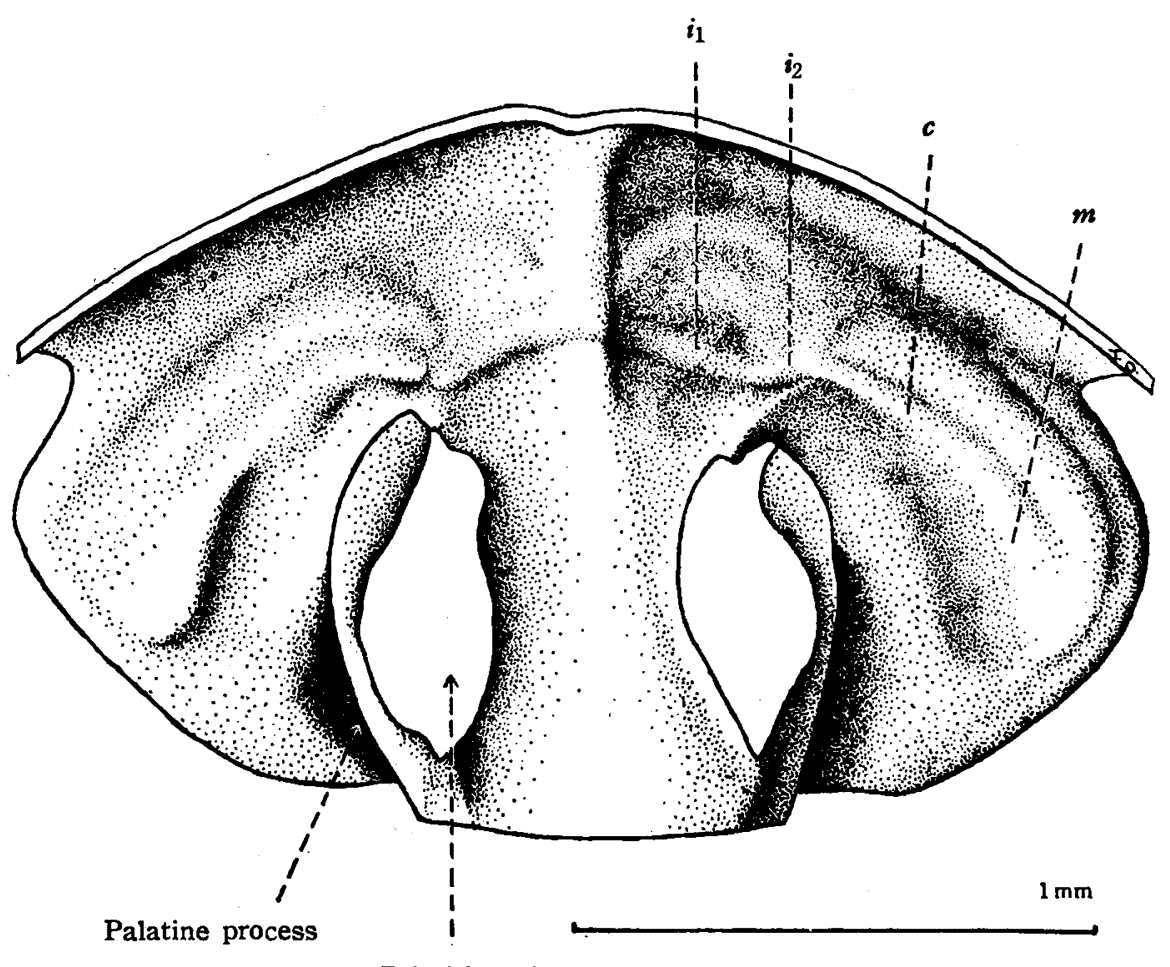

Primitive choana

Fig. 9. No. $100(16 \mathrm{~mm})$.

epithelial band is seen along the dental arch but it bends palatinally in front of the primitive choana. In this specimen the wavy contour 
of the dental lamina is indistinct but the area of $c$ is flattened. The germ $i_{2}$ on the left side seems to be composed of two portions, one in the maxillary process, the other in the medial nasal process.

Stage IV (No. 115, No. 114 and No. 1)

The level of the oral epithelium at the fusion of both facial pro. cesses is pulled down, the primitive choana is elongated. The tendency of the dental lamina to bend palatinalwards in front of the choana is no more present. The dental band projects at the germ $i_{2}$. The dental lamina on both sides becomes at last continuous on the median line.

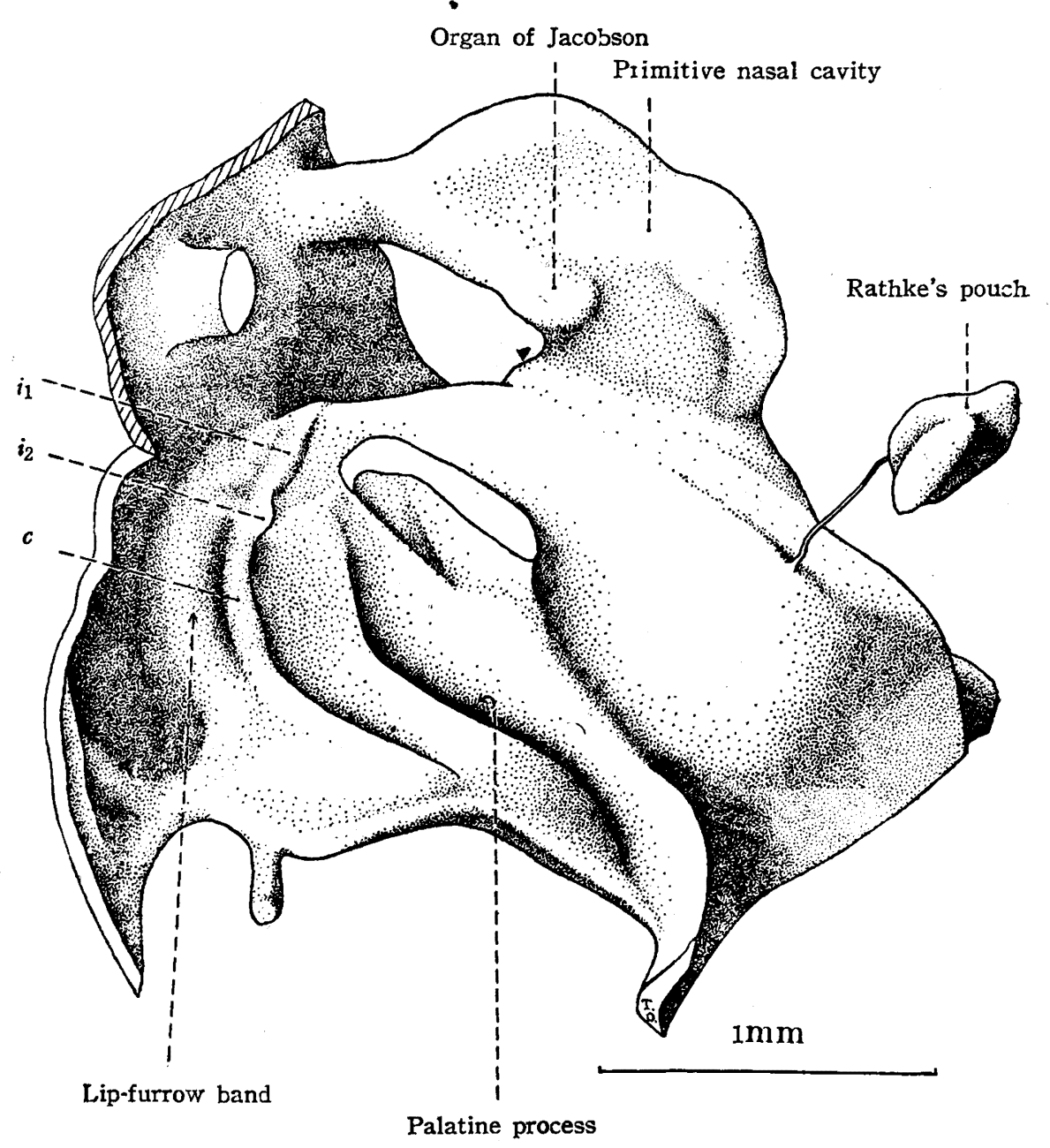

Fig. 10. No. $115(15 \mathrm{~mm})$.

Fig. 10 shows the model of No. $115(15 \mathrm{~mm})$, viewed from the left 
side. On this side the primitive nasal cavity was taken off so that the left dental lamina is clearly seen. Between the germs $i_{1}$ and $i_{2}$ the dental lamina is cut in and the germ $i_{2}$ projects, and the area of germ $c$ is directed slightly to the labial side.

In No. $114(15 \mathrm{~mm})$ which represents a stage a little earlier than other specimens of this group, the germ $i_{2}$ is already slightly projected, while in No. $1(17 \mathrm{~mm})$, an average stage of the group, the projection of the germ $i_{2}$ was hardly noticeable. In addition, it should be noted that on the left side of the latter case the incision of the dental lamina between the germs $i_{1}$ and $i_{2}$ was unusually deep.

Descriptions of the later stages are omitted since they are treated in details in my previous paper.

\section{General observations and discussions}

1) The first sign of the dental anlage is the thickening of the oral epithelium which is already to be found in embryos of $8-9 \mathrm{~mm}$ body length (Fig. 11). In my specimens the time of appearance of the first dental anlage is therefore earlier than that described by previous authors ( $11-13 \mathrm{~mm}, \mathrm{R}$ ös e, $\mathrm{A} \mathrm{hrens}$ and $\mathrm{Orb}$ a n etc.).

2) The epithelial thickening takes place on each facial processes -on mandibular, maxillary and medial nasal processes-and it is interrupted by the nasal pit on the upper jaw. This epithelial thickening, which was used to be called "dental lamina, Zahnleiste", should be called "dental plate, Zahnplatte" at this stage, in analogy to "neural plate, Neuralplatte; nasal plate, Nasenplatte etc.". It is impossible to differenciate the sites of the germs $i_{1}, i_{2}, c$ and $m$ at this stage.

3) Then (in embryos of $11-14 \mathrm{~mm}$ ) the epithelial thickening begins to grow into the mesoderm in its anterior and posterior parts. But the ingrowth in the posterior region is partly due to the depression of the oral cavity. In the lower jaw the ingrowth in the posterior region appears earlier than in the anterior region, while in the upper jaw the anterior ingrowth becomes conspicuous earlier than the posterior (Fig. 12).

4) Later (in embryos of $15 \mathrm{~mm}$ body length), the epithelial ingrowth occurs along the entire length of the dental arch. Even at this stage, however, the free margin of the so-called dental lamina is not linear but posseses a wavy contour, which comes to be found at the very beginning of development (Fig. 13). 
5) On the median line the epithelial thickening and ingrowth appear later than in other areas. The right and left dental germs approach to each other as the development advances. In the upper jaw the distance between the right and left $i_{1}$ is greater than in the lower jaw (Fig. 6, 7, 8 with Fig. 1, 2 and 3, respectively) and it may be the cause of the more frequent median diastema in the upper jaw.

6) The epithelial thickening and ingrowth is present already before the formation of the primary palate. A small part of the upper germ $i_{2}$ can take its origin from the epithelial thickening on the medial nasal process.

7) O r ban (1928) measured the distance between the floor of the nasal cavity and the highest point of the upper dental lamina and found this distance almost constant in various stages. He considered, therefore, that the dental germs develop not from the dental lamina but directly from the oral epithelium itself. After this opinion of Orban to which great importance should be attached, the dental lamina is nothing but a band formed by the developing tooth germs and the oral epithelium included into the mesoderm.

\section{Conclusion and Résumé}

1) The early development of the dental lamina was studied by serial scanning of about 25 human embryos of 4 to $30 \mathrm{~mm}$ body length as well as by preparing reconstruction models.

2) In my specimens the first appearance of the dental anlage was observed already in embryos of $8-9 \mathrm{~mm}$ body length. So the period is slightly earlier than that reported by previous authors.

3) The dental anlage, epithelial thickening, should be called "dental plate, Zahnplatte". It is interrupted by the nasal pit in the upper jaw.

4) The epithelial thickening begins to grow, sooner or later, into the mesoderm in its anterior $\left(i_{1}\right)$ and posterior $(m)$ regions.

5) Even when the ingrowth spreads on the entire length of the prospective dental arch, the free margin of the dental lamina is not linear as demonstrated in many schematic figures. As the development advances each germ becomes more easily differenciable.

The author wishes to express his sincere appreciation to Dr. T. Fujit a (Professor of Anatomy, Tokyo University Medical School) for his kind and precious suggestions. 


\section{Bibliography}

En oki, M., Tooth-genesis in the Guinea-Pig. (Japanese). Shikagaku-Zasshi, Vol. 1, No. 3, 1944 .

K a to, K., Embryological Studies on the Development of the Tooth in Human Embryo, with special reference to the Formation of the Tooth Band and Lip Furrow Band. (Japanese). Acta Inst. Anat. Niigataensia, Vol. 27, 1953.

-K a g a w a, G., Ueber das früheste Stadium der Entwicklung der Zähne des Menschen. Acta. Hist. Jap., Vol. 10, 1956.

O o é, T., On the Development of Position of the Tooth Germs in the Human deciduous Front Teeth. Okajimas Folia Anat. Jap., Bd. 28, 1956.

Orban, B., Growth and Movement of the Tooth Germs and Teeth. J.A. D. A., 1928.

Peter, K., Zur Bildung des Primären Gaumens bei Mensch und Säugetieren. Anat. Anz., Bd. 20, 1902.

" , Modelle zur Entwicklung des menschiichen Gesichtes. Anat. Anz., Bd. 39, 1911.

" . Atlas der Entwicklung der Nase und des Gaumens beim Menschen. Jena, 1913.

R ס̊se, C., Ueber die erste Anlage der Zahnleiste beim. Menschen. Anat. Anz., Bd. 8, 1893.

$\mathrm{Sch}$ ou r, I., Early human tooth development, with special reference to the relationship between the dental lamina and lip-furrow band. Jour. dent. Res., Vol. 9, 1919.

Si cher, H. und Tandler, J., Anatomie für Zahnärzte. Wien u. Berlin. 1928.

Streeter, G., Developmental Horizons in Human Embryos. Description of Age Groups XV, XVI, XVII and XVIII. Contributions to Embryology, Vol. 32, 1948. 


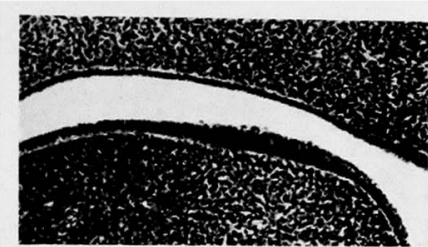

Fig. 11. No. $98(9 \mathrm{~mm}) \times 90$ sagittal section.

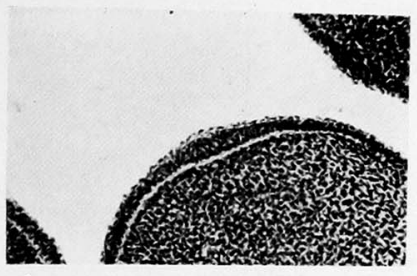

A.

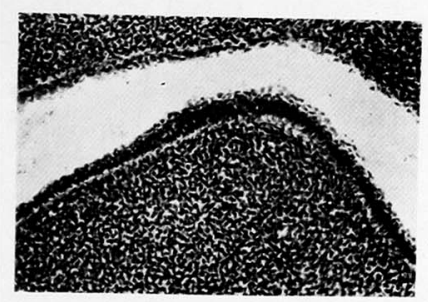

B.

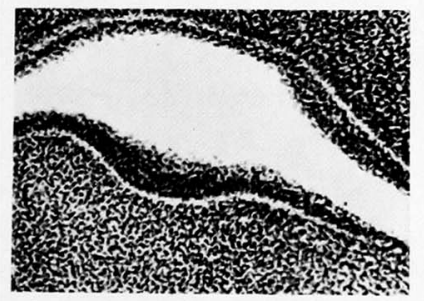

C.

Fig. 12. No. $109(14 \mathrm{~mm}) \times 90$ sagittal section.

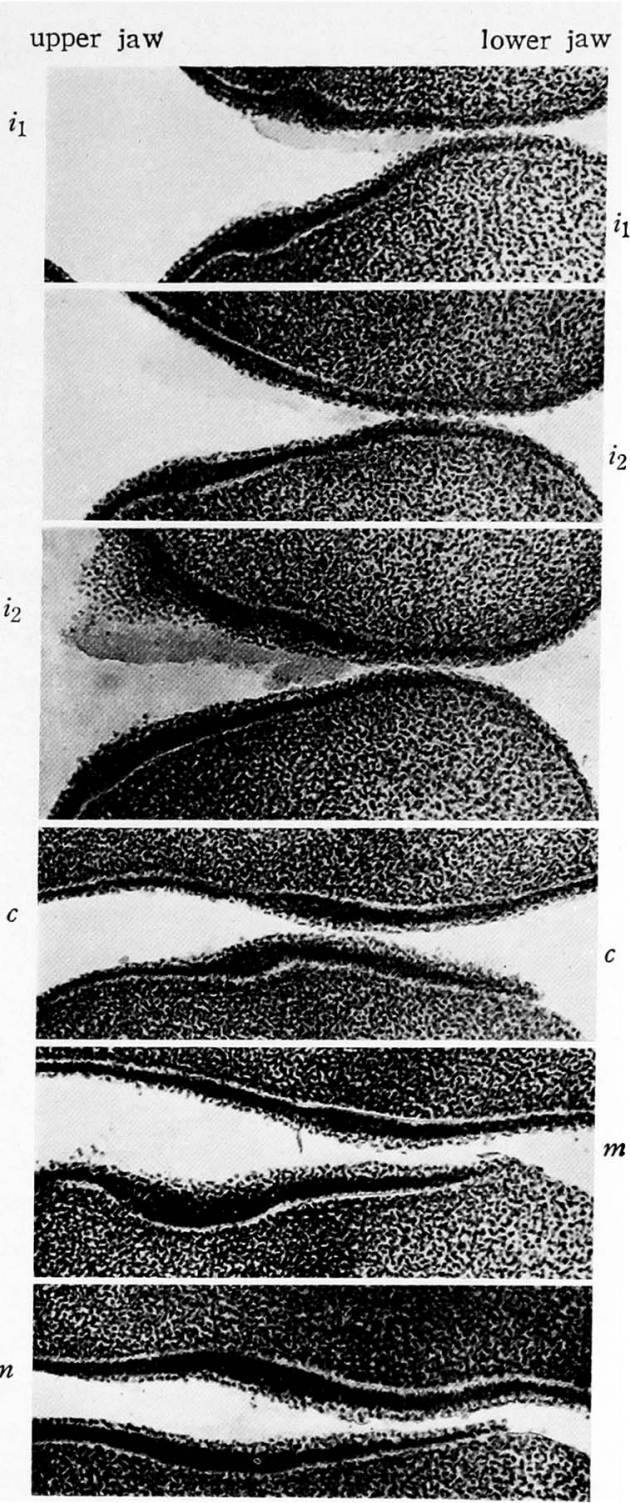

Fig. 13. No. $101(15 \mathrm{~mm}) \times 90$ sagittal section.

Lower figures represent more distal portions of the dental lamina.

T. Ooé 